\title{
Correction to: Web Engineering
}

\author{
Marco Brambilla $(1)$, Richard Chbeir (10), Flavius Frasincar (1), \\ and Ioana Manolescu (D)
}

\section{Correction to: \\ M. Brambilla et al. (Eds.): Web Engineering, LNCS 12706, https://doi.org/10.1007/978-3-030-74296-6}

In Chapter 10, the term "paths" was used instead of the term "operation." This has been corrected and the term "operations" is now used throughout the paper.

In Chapter 26, the email addresses of some authors have been corrected. The corrected email addresses are: dylan.vanassche@ugent.be, gertjan.demulder@ugent.be, and ben. demeester@ugent.be.

The updated version of these chapters can be found at 